\title{
Changing Trends of HIV, Syphilis, and Hepatitis C among Male Migrant Workers in Chongqing, China: Nine Consecutive Cross-Sectional Surveys, 2010-2018
}

\author{
Yujun Wang ${ }^{1,+}$, Rongrong $\mathrm{Lu}^{2,+}$, Guohui $\mathrm{Wu}^{2,+}{ }^{2}$, Rong Lan ${ }^{1}$, Rong Ou ${ }^{3}$, Yangchang Zhang ${ }^{1}$ and \\ Mengliang $\mathrm{Ye}^{1, *(1)}$ \\ 1 Department of Epidemiology and Health Statistics, School of Public Health and Management, Chongqing \\ Medical University, Chongqing 400016, China; cqwangyujun@163.com (Y.W.); lr10769909166@163.com (R.L.); \\ 18702370226@163.com (Y.Z.) \\ 2 Institute for AIDS/STD Control and Prevention, Chongqing Center for Disease Control and Prevention, \\ Chongqing 400042, China; lurrong@163.com (R.L.); wgh68803652@163.com (G.W.) \\ 3 Library of Chongqing Medical University, Chongqing 400016, China; ourong@cqmu.edu.cn \\ * Correspondence: yemengliang@cqmu.edu.cn; Tel.: +86-153-1093-9053 \\ + These authors contributed equally to this work.
}

Received: 21 January 2020; Accepted: 29 January 2020; Published: 30 January 2020

Abstract: Background: Male migrant workers (MMWs) have been reported to be vulnerable to human immunodeficiency virus (HIV) and other sexually transmitted infections (STIs). Chongqing, China is one of the major migration destinations and hotspots of HIV. This study aims to explore the prevalence of HIV, syphilis, and hepatitis C virus (HCV), as well as HIV-related knowledge and behaviors, among MMWs in Chongqing. Methods: Questionnaire surveys were conducted, and blood samples were collected and examined among MMWs selected by two-stage stratified sampling in Chongqing from 2010 to 2018. The Cochran-Armitage trend test was conducted to observe the trends in the prevalence of HIV, syphilis, and HCV, as well as HIV-related knowledge and behaviors. The Chi-square test and Binary Logistic Regression were conducted to observe the distinctions between different groups. Results: The overall HIV prevalence was $0.6 \%$ with an increasing trend $(0.2 \%$ to $0.9 \%, p<0.001)$, whereas the overall $\mathrm{HCV}$ prevalence was $0.5 \%$ with a decreasing trend $(0.5 \%$ to $0.4 \%$, $p<0.001)$. The overall syphilis prevalence was $1.3 \%$ in the $\geq 50$ age group, $1.0 \%$ in the $30-49$ age group, and higher than $0.3 \%$ in the $16-29$ group $\left(X^{2}=19.527, p<0.001\right)$. An uptrend $(80.2 \%-80.6 \%$, $p<0.001)$ was observed in correct HIV-related knowledge. The 16-29 ((Odds Ratio) OR: 1.575; 95\%CI (Confidence Interval): 1.380-1.798; $p<0.001$ ) and 30-49 (OR: 1.697; 95\%CI: 1.495-1.926; $p<0.001$ ) age groups had 1.575 and 1.697 times correct HIV-related knowledge more than the $\geq 50$ age group. The proportion of subjects engaged in commercial sex in the past year $(7.7 \%-13.3 \%, p<0.001)$, consistent condom use during this activity $(20.5 \%-54.0 \%, p<0.001)$, and condom use in the last commercial sex $(48.6 \%-72.1 \%, p=0.020)$ were increasing. The risk of engaging in commercial sex in the past year in the $16-29$ age group was 0.768 times (OR: $0.768 ; 95 \%$ CI: $0.643-0.917 ; p=0.003$ ) less than that in the $\geq 50$ age group. The risk of engaging in non-regular sex in the past year in the 16-29 (OR: 2.819; 95\%CI: $2.317-3.431 ; p<0.001$ ) and 30-49 (OR: 1.432; 95\%CI: 1.184-1.733; $p<0.001$ ) age groups were 2.819 and 1.432 times more than that in the $\geq 50$ age group. The risk of engaging in anal sex in the past year in the 16-29 age group was 6.333 times (OR: 6.333; 95\%CI: $1.468-27.327 ; p<0.013$ ) more than that in the $\geq 50$ age group. The proportion of consistent condom use during non-regular sex in the past year $(10.9 \%-47.3 \%, p<0.001)$ and condom use in the last non-regular sex $(40.8 \%-71.1 \%$, $p<0.001)$ increased remarkably. The possibilities of consistent condom use during commercial sex in the past year in the 16-29 (OR: 2.606; 95\%CI: 1.847-3.677; $p<0.001$ ) and 30-49 (OR: 1.632; 95\%CI: $1.214-2.195 ; p=0.001$ ) age groups were 2.606 and 1.632 times more than that in the $\geq 50$ age group. The possibilities of condom use in the last commercial sex in the 16-29 (OR: 1.805; 95\%CI: 1.258-2.589; $p=0.001$ ) and 30-49 (OR: 1.360; 95\%CI: 1.016-1.821; $p=0.039$ ) age groups were 1.805 and 1.360 times 
more than that in the $\geq 50$ age group. The possibilities of consistent condom use during non-regular sex in the past year (OR: 1.628; 95\%CI: 1.066-2.484; $p=0.024$ ) and condom use in the last non-regular sex (OR: $1.671 ; 95 \%$ CI: $1.148-2.433 ; p=0.007)$ in the $16-29$ age group were 1.628 and 1.671 times more than those in the $\geq 50$ age group, respectively. Conclusion: An upward trend of HIV and a downward trend of HCV were observed among MMWs in Chongqing from 2010 to 2018. We also found an increase in commercial sex and inadequate condom use during high-risk behaviors among this population. The overall syphilis prevalence in the middle-aged and elderly groups was higher than in the young group, and elderly MMWs were more likely to engage in unprotected high-risk behaviors. Thus, targeted STI prevention for MMWs in Chongqing, especially those aged 50 years and above, is urgently needed.

Keywords: male migrant workers; HIV; syphilis; HCV; STIs; Chongqing; cross-sectional survey

\section{Introduction}

HIV is a major contributor to the global burden of disease. In 2010, HIV was the leading cause of disability-adjusted life years worldwide for people aged 30-44 years and the fifth leading cause for all ages [1]. An HIV/AIDS (acquired immune deficiency syndrome) epidemic has been reported in China, with 627,030 people living with HIV/AIDS and 194,435 deaths up to 30 June 2016 [2]. China is experiencing such an HIV epidemic because it has a large population susceptible to infection by high-risk behaviors such as commercial sex, homosexual anal sex, and non-regular sex [3]. Most previous studies and interventions have focused on commercial sex workers, men who have sex with men (MSM), and intravenous drug users; however, increasing domestic migration is a likely factor contributing to the increasing HIV prevalence in China [4-7]. "Agricultural" (rural) and "non-agricultural" (urban) are the two household registration categories available in China [8]. Rapid urbanization and industrialization driven by economic growth in China has resulted in large-scale rural-to-urban migration $[9,10]$. Migrants are individuals of rural origin who migrate to urban areas temporarily in hopes of gaining employment and a chance to reap the benefits of the booming urban economic environment; these migrants are mainly comprised of male migrant workers (MMWs) [11]. Mobility among migrant workers has been found to increase vulnerabilities to sexually transmitted infections (STIs), such as HIV and syphilis [12-15]. This phenomenon has been explained by the separation from long-term partners and increased contact with high-risk partners, such as commercial sex workers [16-18]. Most MMWs migrate to urban areas, where the open cultural environment and availability of convenient services increase their probability of engaging in homosexual anal sex, which partly results in the high infection rates of STIs in this group. The existing household registration system in China hinders migrants from switching from a rural to urban residence permanently. Thus, these migrants become marginalized and cannot access the social welfare available to urban residents, resulting in poor living conditions, adverse employment situations, negligible access to health care services, and lack of social support. These drawbacks increase their risk of contracting HIV [19-21]. Nevertheless, the number of migrant workers has been increasing every year, despite the unfavorable working and living conditions.

As HIV, syphilis, and HCV are all sexually transmitted diseases (STDs) with the same high-risk population, the Chinese government has built a comprehensive surveillance system, including the national sentinel surveillance system, case reporting system, and special epidemiologic surveys [22-24]. In 2010, the number of national sentinel sites expanded from 600 to 1888, covering all of China's 31 provinces (autonomous regions and municipalities) and targeting eight groups (drug users, female sex workers (FSWs), men who have sex with men (MSMs), male STI clinic attendees, long-distance truck drivers, antenatal care clinic attendees, young college students, and MMWs) [25]. In 2015, 34,315 MMWs were monitored at 87 national sentinel sites of China, with overall antibody positive rates 
of HIV, syphilis, and HCV at $0.14 \%, 0.61 \%$, and $0.41 \%$, respectively [26]. A high HIV prevalence among migrants has been reported in several metropolises of China, such as Shanghai and Zhejiang $[4,16]$. These cities represent developed areas; however, data on undeveloped southwest China, with low income and educational levels (which can be important predictors of STIs), have been largely ignored. Chongqing is one of the four municipalities under the direct control of the central government of China and serves as the economic and political center of southwest China, which has made Chongqing a magnet for migrant workers $[27,28]$. The average annual rate for new HIV infections in Chongqing from 2007 to 2012 was $19.7 \%$, which greatly exceeded the national infection rate (3.13\%) [29]. To augment the limited studies on MMWs in Chongqing, the present study adopted serial cross-sectional surveys to explore the prevalence of HIV, syphilis, and HCV among this group and investigated their HIV-related knowledge and behaviors from 2010 to 2018. Conducting a detailed exploration of reliable and accurate data is essential, as the findings could be translated into effective public health interventions to combat the STI epidemic in Chongqing.

\section{Methods}

\subsection{Design}

The study was supported by the Center for Disease Control (CDC) in Chongqing, China and approved by the medical ethics committee of Chongqing Medical University (IRB number: 2017016). According to the requirement of the Protocol for National Sentinel Surveillance of HIV/AIDS in China, the sentinel monitoring period is from April to June every year [25]. Each participant was asked to anonymously complete the questionnaire and was provided with a unique study-specific identification number (UID).

\subsection{Recruitment}

We restricted our samples to men, as migrant workers are mainly (60\%) male and most $(70 \%)$ cases of HIV are concentrated in this gender group $[8,10,11]$. The sample selection was followed by a two-stage stratified sampling strategy. First, we selected the three districts in Chongqing (Yuzhong, Jiangbei, and Jiulongpo) with the largest and densest MMWs among all districts. Second, the sample subjects were recruited from four occupational clusters (construction workers, miners, enterprise workers, and business operators), which together composed a large proportion of Chongqing's MMWs. The inclusion criteria for the study participants were as follows: (1) aged at least 16 years; (2) household registration not belonging to a local district; and (3) volunteered to participate in this study. Permanent MMWs were excluded, as they had no intention to return to their places of origin and, thus, do not serve as a bridge population for transmission. Before the interviews, the researchers explained to the respondents that the data collected would be confidential and used strictly for academic purposes, and 20 Chinese Yuan was paid as an incentive. To ensure privacy during the survey, one investigator alone interviewed one participant in a private room during their rest time. Informed consent and blood collection for laboratory analysis was obtained prior to the questionnaire survey. The survey took approximately 30 to 75 minutes to complete. Finally, 11,252 MMWs were recruited in our study.

\subsection{Measures}

The serial cross-sectional surveys comprised the national unified sentinel surveillance questionnaire covering socio-demographics as well as HIV-related knowledge and behaviors; furthermore, sero-testing for HIV, syphilis, and HCV was conducted among the MMWs in Chongqing from 2010 to 2018.

\subsubsection{Socio-Demographics, HIV-Related Knowledge, and Behaviors}

The socio-demographic information included age, marital status (never married/married/never married but cohabited/divorced or widowed), household registration (Chongqing/other provinces), 
occupation (construction worker/miner/enterprise worker/business operator/others), local residence time ( $<3$ months/3-6 months/6-12 months/ $>1$ year), and educational level (primary or lower/junior high school/senior high school or above).

HIV-related knowledge and behaviors were selected, as HIV was the most serious of the three STDs with common transmission routes in our study. We asked the participants to identify transmission modes from eight questions by answering "Yes," "No," or "Unknown". Correct responses to at least $75 \%$ of the questions indicated having adequate correct knowledge. The eight items were as follows: (1) people living with HIV can definitely be identified by observing their physical appearance; (2) mosquito bites can spread AIDS; (3) eating with people living with HIV can lead to an HIV infection; (4) the input of HIV-infected blood can lead to an HIV infection; (5) sharing syringes with people living with HIV can lead to AIDS; (6) children born to HIV-infected women can acquire AIDS; (7) consistent condom use can reduce the risk of HIV transmission; and (8) sexual intercourse with only one partner can reduce the spread of AIDS. The internal consistency of this scale was 0.83 .

To understand sexual behavioral patterns, we collected information about the respondents' experience in commercial sex with a female, non-regular sex with a female, and anal sex with a male in the past year (i.e., the respondents answered with a "yes" or "no"). Non-regular sex was defined as sexual intercourse with another person without pay or plans for a long-term relationship [9]. Consistent and correct condom use during high-risk sexual behaviors could depress the risk of HIV infection by approximately $69 \%[30,31]$. Thus, the frequencies of condom use during these sexual acts in the past year and in the last sexual encounter were asked in order to evaluate condom use patterns (e.g., never, sometimes, and always). Consistent condom use was defined as "Always," and options of "Never" and "Sometimes" were regarded as inconsistent condom use. The lifetime history of drug use was also enquired (i.e., the respondents answered with a "yes" or "no").

\subsubsection{Sero-Testing}

Exactly $5 \mathrm{~mL}$ of venous blood sample was collected from each participant for HIV, syphilis, and $\mathrm{HCV}$ antibody testing by using the standard protocol and laboratory methods of the National Center for AIDS Prevention and Control in China [32]. For HIV and HCV, the samples that tested positive in the highly sensitive enzyme-linked immunosorbent assay (ELISA) test ELISA-1 were subjected to a highly specific ELISA (ELISA-2), and then were confirmed to be positive [33]. Syphilis antibodies were screened using the ELISA test, and positives were confirmed by treponema pallidum particle assay (TPPA) [34]. All the screening and confirmatory tests were conducted at designated and certified laboratories in local CDC or CDC-accredited hospitals. The anonymous test results were linked with the interview data through the UIDs.

\subsection{Data Quality Control}

The surveys and the serological testing were conducted by doctors at the Center for Disease Control (CDC) in Chongqing, China. The same sampling design and the training module for doctors were used at all sites. Among the eligible subjects, those who had already participated in this survey in Chongqing during the same year were excluded. The answers to the questionnaire were checked by senior investigators to ensure the completeness of the survey. The results were entered into the database by designated personnel who were blind to the field survey.

\subsection{Data Analysis}

Collected questionnaire data, along with the results of the serological tests in our serial cross-sectional surveys, were entered into the database management system of the National HIV/AIDS surveillance in China and exported from the system. The respondent's socio-demographic characteristics; infection rates of HIV, syphilis, and HCV; and HIV-related knowledge and behaviors were described by number and percentages. The Chi-square test and Binary Logistic Regression were 
conducted to observe the differences between different age groups. The trends from 2010 to 2018 were tested using the Cochran-Armitage trend test. All analyses were conducted with the SPSS20.0 software.

\section{Results}

\subsection{Socio-Demographic Characteristics}

Data were obtained from 11,252 MMWs. Among them, most (46.9\% in 2010 to $44.3 \%$ in 2018 ) were aged $30-49$ years; more than $50 \%$ (63.9\% in 2010 to $54.1 \%$ in 2018 ) were married; most (53.6\% in 2010 to $74.1 \%$ in 2018) were from Chongqing and the remainder were from other provinces; the minority ( $23.1 \%$ in 2010 to $7.0 \%$ in 2018 ) had primary school or less education; the majority ( $43.4 \%$ in 2011 to $51.2 \%$ in 2018) had lived in Chongqing for more than 1 year; and the minority $(0.3 \%$ in 2011 to $0.0 \%$ in 2018) were miners (see Table 1).

\subsection{Prevalence and Trends of HIV, Syphilis, and HCV}

During the study period, the overall HIV prevalence was $0.6 \%$ with an increasing trend $(0.2 \%$ in 2010 to $0.9 \%$ in $2018, p<0.001$ ) among MMWs in Chongqing. Unlike HIV, the overall prevalence of HCV was $0.5 \%$ with a decreasing trend $(0.5 \%$ in 2010 to $0.4 \%$ in $2018, p<0.001)$. The prevalence of syphilis was $0.6 \%$ in 2010 and $0.7 \%$ in 2018 and did not significantly change among MMWs in Chongqing. The prevalence of HIV and HCV dropped considerably from 2014 to 2016. Syphilis prevalence also dropped greatly during 2014-2015 and 2016-2017. However, syphilis prevalence increased from 2015-2016 and HIV prevalence increased from 2016-2017 (Figure 1).

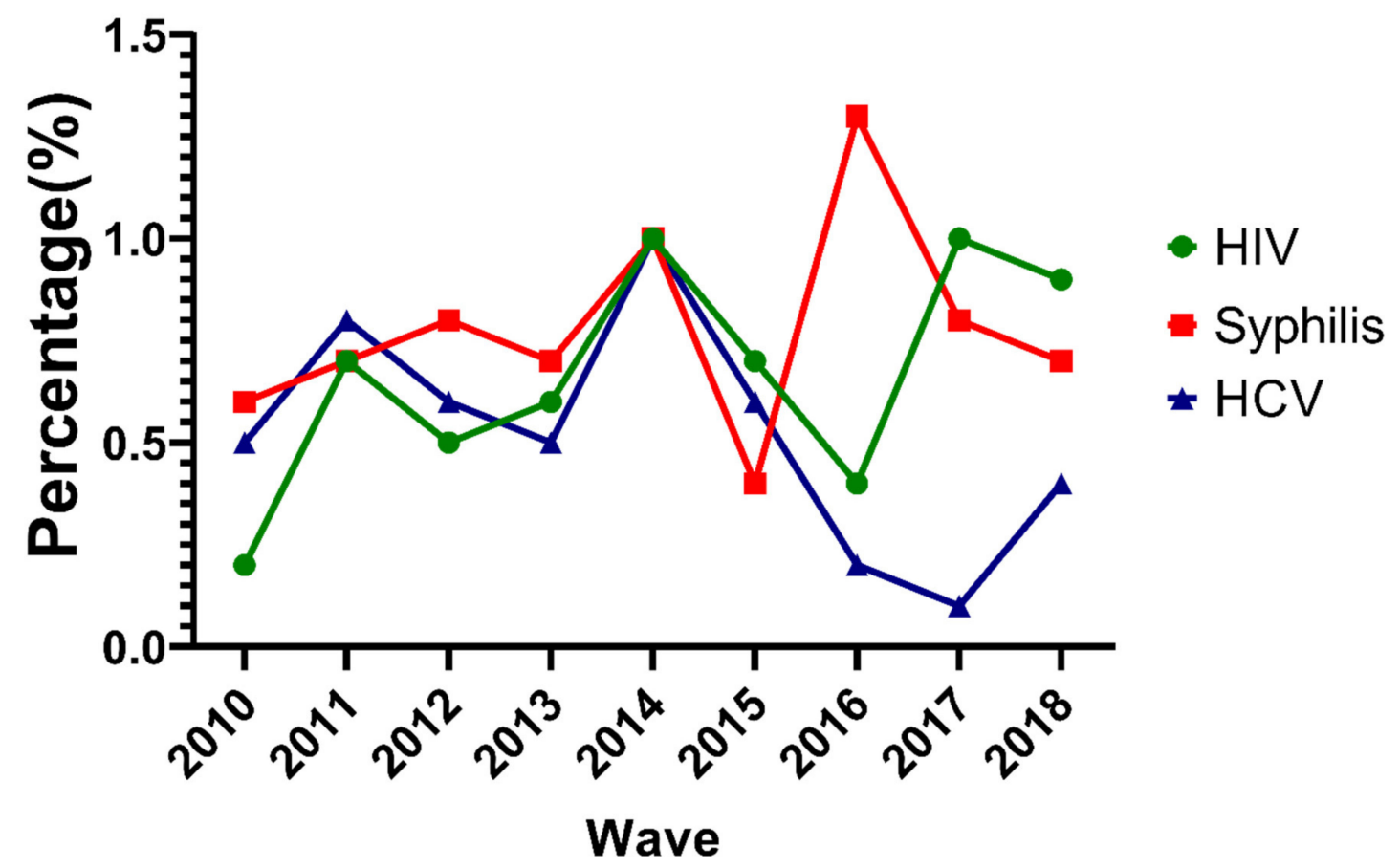

Figure 1. Trends of HIV, syphilis, and hepatitis $\mathrm{C}$ virus (HCV) prevalence for male migrant workers (MMWs) in Chongqing from 2010 to 2018. 
Table 1. Socio-demographic characteristics of male migrant workers (MMWs) between 2010 and 2018 in Chongqing $(N=11,252)$.

\begin{tabular}{|c|c|c|c|c|c|c|c|c|c|}
\hline Variables & $\begin{array}{c}2010(\%) \\
(N=1208)\end{array}$ & $\begin{array}{c}2011(\%) \\
(N=1203)\end{array}$ & $\begin{array}{c}2012(\%) \\
(N=1200)\end{array}$ & $\begin{array}{c}2013(\%) \\
(N=1600)\end{array}$ & $\begin{array}{c}2014(\%) \\
(N=1203)\end{array}$ & $\begin{array}{c}2015(\%) \\
(N=1200)\end{array}$ & $\begin{array}{c}2016(\%) \\
(N=1200)\end{array}$ & $\begin{array}{c}2017(\%) \\
(N=1227)\end{array}$ & $\begin{array}{c}2018(\%) \\
(N=1211)\end{array}$ \\
\hline \multicolumn{10}{|l|}{ Age (year) } \\
\hline $16-29$ & $(465) 38.5 \%$ & $(459) 38.2 \%$ & $(605) 50.4 \%$ & $(584) 36.5 \%$ & (352)29.3\% & (397)33.1\% & (317)26.4\% & (346)28.2\% & (473)39.1\% \\
\hline $30-49$ & (566) $46.9 \%$ & (603)50.1\% & $(461) 38.4 \%$ & $(827) 51.7 \%$ & (570) $47.4 \%$ & $(554) 46.2 \%$ & (670)55.8\% & $(657) 53.5 \%$ & (536) $44.3 \%$ \\
\hline $50-$ & (177) $14.7 \%$ & (141) $11.7 \%$ & $(134) 11.2 \%$ & (189) $11.8 \%$ & (281) $23.4 \%$ & (249) $20.8 \%$ & (213)17.8\% & (224)18.3\% & (202) $16.7 \%$ \\
\hline \multicolumn{10}{|l|}{ Marital status } \\
\hline Never married & (311)25.7\% & (341)28.3\% & $(380) 31.7 \%$ & (332)20.8\% & $(188) 15.6 \%$ & (179)14.9\% & (170)14.2\% & (153) $12.5 \%$ & (349)28.8\% \\
\hline Married & (772) $63.9 \%$ & $(748) 62.2 \%$ & (609)50.8\% & (1126)70.4\% & $(841) 69.9 \%$ & $(818) 68.2 \%$ & $(832) 69.3 \%$ & (776) $63.2 \%$ & (655)54.1\% \\
\hline $\begin{array}{c}\text { Never married but } \\
\text { cohabited }\end{array}$ & (111)9.2\% & $(94) 7.8 \%$ & (200)16.7\% & $(124) 7.8 \%$ & (122) $10.1 \%$ & (181)15.1\% & (176)14.7\% & (253)20.6\% & $(165) 13.6 \%$ \\
\hline \multicolumn{10}{|l|}{ Household register } \\
\hline Chongqing & $(648) 53.6 \%$ & $(893) 74.2 \%$ & $(868) 72.3 \%$ & $(632) 39.5 \%$ & (577) $48.0 \%$ & $(922) 76.8 \%$ & $(879) 73.2 \%$ & (978)79.7\% & $(897) 74.1 \%$ \\
\hline $\begin{array}{l}\text { Other province } \\
\text { Education }\end{array}$ & (560) $46.4 \%$ & (310) $25.8 \%$ & (332) $27.7 \%$ & (968)60.5\% & (626) $52.0 \%$ & $(278) 23.2 \%$ & (321) $26.8 \%$ & (249)20.3\% & (314) $25.9 \%$ \\
\hline Primary or less & (278)23.1\% & $(225) 18.7 \%$ & $(146) 12.2 \%$ & (309)19.3\% & (227) $18.9 \%$ & $(107) 8.9 \%$ & (132)11.0\% & $(101) 8.3 \%$ & $(85) 7.0 \%$ \\
\hline Junior high school & (639) $53.1 \%$ & (508) $42.3 \%$ & $(453) 37.8 \%$ & $(684) 42.8 \%$ & $(506) 42.1 \%$ & $(475) 39.6 \%$ & $(551) 45.9 \%$ & $(467) 38.2 \%$ & $(431) 35.7 \%$ \\
\hline Senior high school or above & (286) $23.8 \%$ & $(469) 39.0 \%$ & $(601) 50.1 \%$ & $(607) 37.9 \%$ & (470)39.1\% & (618) $51.5 \%$ & $(517) 43.1 \%$ & $(655) 53.6 \%$ & $(692) 57.3 \%$ \\
\hline \multicolumn{10}{|l|}{ Local residence time } \\
\hline$<3$ months & $(135) 11.2 \%$ & (99)8.2\% & $(114) 9.5 \%$ & $(72) 4.5 \%$ & (142)11.8\% & $(86) 7.2 \%$ & $(106) 8.8 \%$ & (134)11.0\% & (209)17.3\% \\
\hline $3-6$ months & (278) $23.1 \%$ & $(142) 11.8 \%$ & (256) $21.3 \%$ & $(126) 7.9 \%$ & (161) $13.4 \%$ & $(122) 10.2 \%$ & $(140) 11.7 \%$ & $(202) 16.5 \%$ & (156) $12.9 \%$ \\
\hline 6-12 months & (268) $22.3 \%$ & (172) $14.3 \%$ & (346) $28.8 \%$ & $(281) 17.6 \%$ & (239) $19.9 \%$ & (259) $21.6 \%$ & (319) $26.6 \%$ & $(334) 27.3 \%$ & $(225) 18.6 \%$ \\
\hline$>1$ year & (523) $43.4 \%$ & (790) $65.7 \%$ & $(484) 40.3 \%$ & (1121)70.1\% & (661)54.9\% & (733) $61.1 \%$ & $(635) 52.9 \%$ & (553) $45.2 \%$ & $(618) 51.2 \%$ \\
\hline \multicolumn{10}{|l|}{ Sample source } \\
\hline Construction worker & (572) $47.9 \%$ & (215)17.9\% & (220)18.3\% & $(563) 35.2 \%$ & (379)31.5\% & (214) $17.8 \%$ & (291)24.2\% & (272)22.1\% & (193)15.9\% \\
\hline Miner & (3) $0.3 \%$ & (0) $0.0 \%$ & (1) $0.1 \%$ & (16) $1.0 \%$ & (6) $0.5 \%$ & (9) $0.8 \%$ & (8) $0.7 \%$ & (18) $1.5 \%$ & (0) $0.0 \%$ \\
\hline Enterprise worker & (226) $18.9 \%$ & (232)19.3\% & (359) $29.9 \%$ & (286) $17.9 \%$ & (425)35.3\% & $(444) 37.0 \%$ & $(444) 36.9 \%$ & $(424) 34.5 \%$ & (372) $30.7 \%$ \\
\hline Business operation & (166) $13.9 \%$ & (699)58.1\% & $(547) 45.6 \%$ & (408)25.5\% & (152) $12.6 \%$ & (205) $17.1 \%$ & $(204) 16.9 \%$ & (116)9.4\% & (165) $13.6 \%$ \\
\hline Others & (226) $18.9 \%$ & $(57) 4.7 \%$ & (73) $6.1 \%$ & (327) $20.4 \%$ & $(241) 20.0 \%$ & (328) $27.3 \%$ & $(257) 21.3 \%$ & (398)32.4\% & $(482) 39.8 \%$ \\
\hline
\end{tabular}


The overall prevalence of syphilis was $1.3 \%$ in the $\geq 50$ age group, $1.0 \%$ in the $30-49$ age group, and higher than $0.3 \%$ in the $16-29$ group $\left(X^{2}=19.527, p<0.001\right.$; Figure 2$)$.

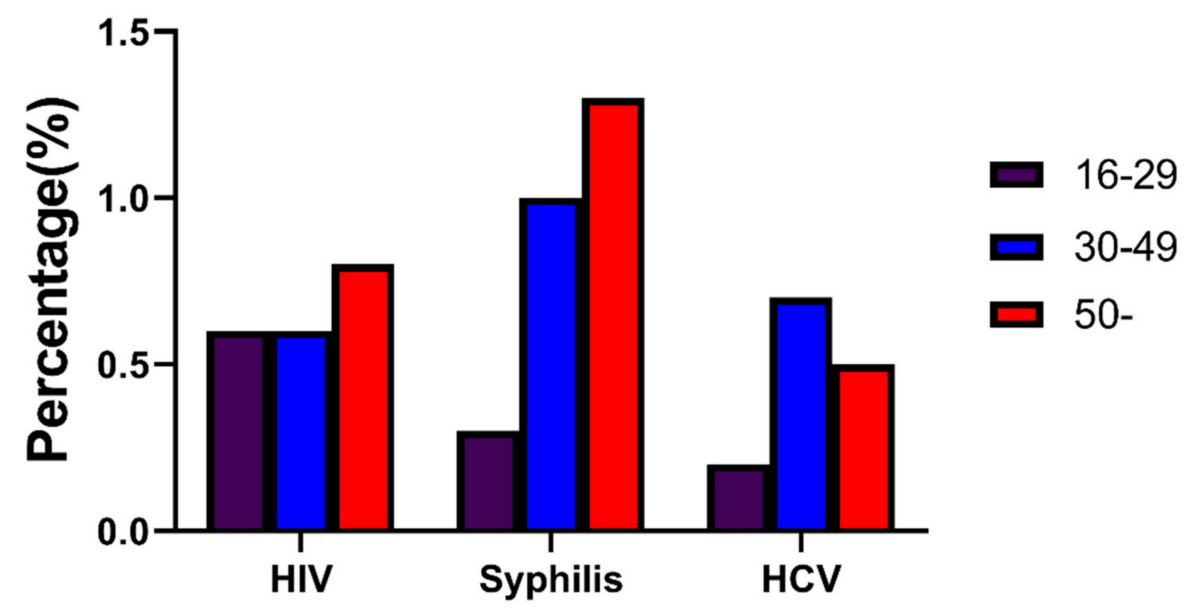

Figure 2. Overall prevalence of HIV, syphilis, and HCV for MMWs of three age groups in Chongqing from 2010 to 2018.

\subsection{HIV-Related Knowledge and Behaviors}

\subsubsection{HIV-Related Knowledge}

Approximately 9136 (81.2\%) participants had correct knowledge regarding HIV, which showed an uptrend (80.2\% in 2010 to $80.6 \%$ in 2018, $p<0.001$; see Table 2). The 16-29 ([Odds Ratio] OR: $1.575 ; 95 \%$ CI [Confidence Interval]: 1.380-1.798; $p<0.001$ ) and 30-49 (OR: 1.697; 95\% CI: 1.495-1.926; $p<0.001$ ) age groups had 1.575 and 1.697 times correct HIV-related knowledge more than the $\geq 50$ age group, respectively (Table 3 ).

\subsubsection{HIV-Related Risk Behaviors}

Approximately 1346 (14.3\%) participants had engaged in commercial sex with a female in the past year with an increasing trend $(7.7 \%$ in 2010 to $13.3 \%$ in 2018, $p<0.001)$. Approximately $1245(12.9 \%)$ and $40(0.4 \%)$ participants engaged in non-regular sex with a female and anal sex with a male in the past year, while significant trends were not found among MMWs in Chongqing from 2010 to 2018. In addition, $25(0.2 \%)$ respondents had experience with drug usage, and no change was observed from 2010 to 2018 (Table 2).

The risk of engaging in commercial sex with a female in the past year in the 16-29 age group was 0.768 times (OR: $0.768 ; 95 \%$ CI: $0.643-0.917 ; p=0.003$ ) less than that in the $\geq 50$ age group. The risk of engaging in non-regular sex with a female in the past year in the 16-29 (OR: 2.819; 95\% CI: 2.317-3.431; $p<0.001$ ) and 30-49 (OR: 1.432; 95\% CI: 1.184-1.733: $p<0.001$ ) age groups were 2.819 and 1.432 times more than that in the $\geq 50$ age group, respectively. The risk of engaging in anal sex with a male in the past year in the 16-29 age group was 6.333 times (OR: 6.333; 95\% CI: 1.468-27.327; $p<0.013$ ) more than that in the $\geq 50$ age; group (Table 3 ). 
Table 2. HIV-related knowledge and behaviors among MMWs between 2010 and 2018 in Chongqing.

\begin{tabular}{|c|c|c|c|c|c|c|c|c|c|c|c|}
\hline Variables & 2010(\%) & 2011(\%) & $2012(\%)$ & $2013(\%)$ & 2014(\%) & 2015(\%) & $2016(\%)$ & $2017(\%)$ & 2018(\%) & $\begin{array}{l}\text { Chi-square } \\
\text { Value }\end{array}$ & $\begin{array}{l}p \text {-Value for } \\
\text { Trend }\end{array}$ \\
\hline Correct HIV-related knowledge & $\begin{array}{c}(969 / 1208) \\
80.2 \%\end{array}$ & $\begin{array}{c}(903 / 1203) \\
75.1 \%\end{array}$ & $\begin{array}{c}(996 / 1200) \\
83.0 \%\end{array}$ & $\begin{array}{c}(1237 / 1600) \\
77.3 \%\end{array}$ & $\begin{array}{c}(923 / 1203) \\
767 \%\end{array}$ & $(1080 / 1200)$ & $\begin{array}{c}(1029 / 1200) \\
858 \%\end{array}$ & $\begin{array}{c}(1023 / 1227) \\
834 \%\end{array}$ & $\begin{array}{c}(976 / 1211) \\
80 \% \%\end{array}$ & 27.503 & $<0.001$ \\
\hline Engaged in commercial sex with female in the & $(74 / 962)$ & $(94 / 935)$ & $(114 / 892)$ & $(125 / 1172)$ & $(176 / 1120)$ & $(190 / 1074)$ & $(298 / 1102)$ & $(136 / 1132)$ & $(139 / 1046)$ & \multirow[b]{2}{*}{55.227} & \multirow{2}{*}{$<0.001$} \\
\hline past year & $7.7 \%$ & $10.1 \%$ & $12.8 \%$ & $10.7 \%$ & $15.7 \%$ & $17.7 \%$ & $27.0 \%$ & $12.0 \%$ & $13.3 \%$ & & \\
\hline Consistently used condom during commercial & $(15 / 73)$ & $(36 / 94)$ & $(49 / 114)$ & $(43 / 125)$ & $(70 / 177)$ & $(73 / 194)$ & $(146 / 298)$ & $(63 / 136)$ & (75/139) & \multirow[b]{2}{*}{22.691} & \multirow[b]{2}{*}{$<0.001$} \\
\hline sex with female in the past year & $20.5 \%$ & $38.3 \%$ & $43.0 \%$ & $34.4 \%$ & $39.5 \%$ & $37.6 \%$ & $49.0 \%$ & $46.3 \%$ & $54.0 \%$ & & \\
\hline Used condom in last commercial sex with & $(36 / 74)$ & $(68 / 94)$ & $(87 / 113)$ & $(82 / 125)$ & $(128 / 175)$ & $(117 / 194)$ & $(217 / 298)$ & $(105 / 135)$ & $(98 / 136)$ & \multirow{2}{*}{5.406} & \multirow{2}{*}{0.020} \\
\hline female & $48.6 \%$ & $72.3 \%$ & $77.0 \%$ & $65.6 \%$ & $73.1 \%$ & $60.3 \%$ & $72.8 \%$ & $77.8 \%$ & $72.1 \%$ & & \\
\hline Engaged in non-regular (unpaid) sex with & $(102 / 960)$ & $(86 / 929)$ & $(162 / 890)$ & $(120 / 1387)$ & $(180 / 1119)$ & $(178 / 1084)$ & $(173 / 1102)$ & $(115 / 1132)$ & $(129 / 1044)$ & \multirow{2}{*}{2.757} & \multirow{2}{*}{0.097} \\
\hline female in the past year & $10.6 \%$ & $9.3 \%$ & $18.2 \%$ & $8.7 \%$ & $16.1 \%$ & $16.4 \%$ & $15.7 \%$ & $10.2 \%$ & $12.4 \%$ & & \\
\hline Consistently used condom during non-regular & $(11 / 101)$ & $(30 / 86)$ & $(39 / 162)$ & $(24 / 120)$ & $(50 / 181)$ & $(44 / 179)$ & (55/173) & $(68 / 115)$ & $(62 / 131)$ & \multirow{2}{*}{52.519} & \multirow{2}{*}{$<0.001$} \\
\hline (unpaid) sex with female in the past year & $10.9 \%$ & $34.9 \%$ & $24.1 \%$ & $20.0 \%$ & $27.6 \%$ & $24.6 \%$ & $31.8 \%$ & $59.1 \%$ & $47.3 \%$ & & \\
\hline Used condom in the last non-regular (unpaid) & $(42 / 103)$ & $(56 / 87)$ & $(100 / 162)$ & $(80 / 120)$ & $(107 / 180)$ & $(84 / 179)$ & $(119 / 173)$ & $(84 / 111)$ & (91/128) & \multirow{2}{*}{16.579} & \multirow{2}{*}{$<0.001$} \\
\hline sex with female & $40.8 \%$ & $64.4 \%$ & $61.7 \%$ & $66.7 \%$ & $59.4 \%$ & $46.9 \%$ & $68.8 \%$ & $75.7 \%$ & $71.1 \%$ & & \\
\hline & $(2 / 967)$ & $(6 / 937)$ & $(1 / 898)$ & $(8 / 1174)$ & $(6 / 1133)$ & $(5 / 1082)$ & $(7 / 1102)$ & $(4 / 1128)$ & $(1 / 1044)$ & \multirow{2}{*}{0.143} & \multirow{2}{*}{0.705} \\
\hline Engaged in anal sex with male in the past year & $0.2 \%$ & $0.6 \%$ & $0.1 \%$ & $0.7 \%$ & $0.5 \%$ & $0.5 \%$ & $0.6 \%$ & $0.4 \%$ & $0.1 \%$ & & \\
\hline Consistently used condom during anal sex & $(0 / 0)$ & $(1 / 6)$ & $(0 / 0)$ & $(1 / 8)$ & $(1 / 6)$ & $(2 / 6)$ & $(1 / 7)$ & $(2 / 4)$ & $(1 / 1)$ & \multirow{2}{*}{2.763} & \multirow{2}{*}{0.096} \\
\hline with male in the past year & $0.0 \%$ & $16.7 \%$ & $0.0 \%$ & $12.5 \%$ & $16.7 \%$ & $33.3 \%$ & $14.3 \%$ & $50.0 \%$ & $100.0 \%$ & & \\
\hline Used condom in the lact anal cer writh mal & $(0 / 0)$ & $(3 / 6)$ & $(0 / 0)$ & $(2 / 8)$ & $(3 / 5)$ & $(3 / 6)$ & $(4 / 7)$ & $(2 / 4)$ & $(1 / 1)$ & \multirow{2}{*}{2.141} & \multirow{2}{*}{0.143} \\
\hline Used condom in the last anal sex with male & $0.0 \%$ & $50.0 \%$ & $0.0 \%$ & $25.0 \%$ & $60.0 \%$ & $50.0 \%$ & $57.1 \%$ & $50.0 \%$ & $100.0 \%$ & & \\
\hline Used druo in lifetim & $(0 / 0)$ & $(4 / 1203)$ & $(3 / 1196)$ & $(1 / 1597)$ & $(3 / 1200)$ & $(6 / 1197)$ & $(4 / 1200)$ & $(3 / 1227)$ & $(1 / 1211)$ & \multirow{2}{*}{0.459} & \multirow{2}{*}{0.498} \\
\hline Used drug in lifetim & $0.0 \%$ & $0.3 \%$ & $0.3 \%$ & $0.1 \%$ & $0.3 \%$ & $0.5 \%$ & $0.3 \%$ & $0.2 \%$ & $0.1 \%$ & & \\
\hline
\end{tabular}


Table 3. The distinctions of HIV-related knowledge and behaviors between different age groups.

\begin{tabular}{|c|c|c|c|c|}
\hline Variable & $\beta$ Value & Wald Value & $p$-Value & $\begin{array}{l}\text { [Odds Ratio] OR }(95 \% \mathrm{CI} \\
\text { [Confidence Interval]) }\end{array}$ \\
\hline \multicolumn{5}{|c|}{ Correct HIV-related knowledge (reference group: $\geq 50$ ) } \\
\hline $16-29$ & 0.454 & 45.125 & $<0.001$ & $1.575(1.380-1.798)$ \\
\hline $30-49$ & 0.529 & 66.736 & $<0.001$ & $1.697(1.495-1.926)$ \\
\hline \multicolumn{5}{|c|}{ Engaged in commercial sex with female in the past year (reference group: $\geq 50$ ) } \\
\hline $16-29$ & -0.264 & 8.537 & 0.003 & $0.768(0.643-0.917)$ \\
\hline $30-49$ & -0.002 & 0.001 & 0.979 & $0.998(0.858-1.161)$ \\
\hline \multicolumn{5}{|c|}{ Consistently used condom during commercial sex with female in the past year (reference group: $\geq 50$ ) } \\
\hline $16-29$ & 0.958 & 29.754 & $<0.001$ & $2.606(1.847-3.677)$ \\
\hline $30-49$ & 0.490 & 10.511 & 0.001 & $1.632(1.214-2.195)$ \\
\hline \multicolumn{5}{|c|}{ Used condom in the last commercial sex with female (reference group: $\geq 50$ ) } \\
\hline $16-29$ & 0.591 & 10.281 & 0.001 & $1.805(1.258-2.589)$ \\
\hline $30-49$ & 0.308 & 4.270 & 0.039 & $1.360(1.016-1.821)$ \\
\hline \multicolumn{5}{|c|}{ Engaged in non-regular (unpaid) sex with female in the past year (reference group: $\geq 50$ ) } \\
\hline $16-29$ & 1.036 & 107.086 & $<0.001$ & $2.819(2.317-3.431)$ \\
\hline $30-49$ & 0.359 & 13.678 & $<0.001$ & $1.432(1.184-1.733)$ \\
\hline \multicolumn{5}{|c|}{ Consistently used condom during non-regular (unpaid) sex with female in the past year (reference group: $\geq 50$ ) } \\
\hline $16-29$ & 0.487 & 5.099 & 0.024 & $1.628(1.066-2.484)$ \\
\hline $30-49$ & 0.249 & 1.350 & 0.245 & $1.282(0.843-1.951)$ \\
\hline \multicolumn{5}{|c|}{ Used condom in the last non-regular (unpaid) sex with female (reference group: $\geq 50$ ) } \\
\hline $16-29$ & 0.513 & 7.173 & 0.007 & $1.671(1.148-2.433)$ \\
\hline $30-49$ & 0.167 & 0.803 & 0.370 & $1.182(0.820-1.703)$ \\
\hline \multicolumn{5}{|c|}{ Engaged in anal sex with male in the past year (reference group: $\geq 50$ ) } \\
\hline $16-29$ & 1.846 & 6.121 & 0.013 & $6.333(1.468-27.327)$ \\
\hline $30-49$ & 1.230 & 2.749 & 0.097 & $3.423(0.799-14.657)$ \\
\hline
\end{tabular}




\subsubsection{Condom Use During HIV-Related Risk Behaviors}

The proportion of consistent condom use during commercial sex with a female in the past year ( $20.5 \%$ in 2010 to $54.0 \%$ in $2018, p<0.001)$ and condom use in the last commercial sex $(48.6 \%$ in 2010 to $72.1 \%$ in $2018, p<0.020$ ) dramatically increased. The proportion of consistent condom use during non-regular sex with a female in the past year $(10.9 \%$ in 2010 to $47.3 \%$ in $2018, p<0.001)$ and condom use in the last non-regular sex $(40.8 \%$ in 2010 to $71.1 \%$ in 2018, $p<0.001)$ increased remarkably. Approximately $9(22.5 \%)$ participants used condoms consistently during anal sex with a male in the past year and $18(45.0 \%)$ participants used condoms in the last anal sex, but no significant trends were observed among MMWs in Chongqing from 2010 to 2018 (Table 2).

The possibilities of consistent condom use during commercial sex with a female in the past year in the 16-29 (OR: 2.606; 95\% CI: 1.847-3.677; $p<0.001$ ) and 30-49 (OR: 1.632; 95\% CI: 1.214-2.195; $p=0.001$ ) age groups were 2.606 and 1.632 times more than that in the $\geq 50$ age group, respectively. The possibilities of condom use in the last commercial sex in the 16-29 (OR: 1.805; 95\% CI: 1.258-2.589; $p=0.001$ ) and 30-49 (OR: 1.360; 95\% CI: 1.016-1.821; $p=0.039$ ) age groups were 1.805 and 1.360 times more than that in the $\geq 50$ age group, respectively. The possibilities of consistent condom use during non-regular sex with a female in the past year (OR: 1.628; 95\% CI: 1.066-2.484; $p=0.024$ ) and condom use in the last non-regular sex (OR: 1.671; 95\% CI: 1.148-2.433; $p=0.007$ ) in the 16-29 age group were 1.628 and 1.671 times more than those in the $\geq 50$ age group, respectively (Table 3 ).

\section{Discussion}

Knowing the trends of infectious diseases such as HIV, syphilis, and HCV is critical for their control in China, as they cumulatively constitute a worrisome public health challenge; particularly among high-risk groups including MMWs. Chongqing is one of the busiest regions for the inflow of China's migrant population. Therefore, we investigated the prevalence of these diseases and relevant knowledge and behaviors of MMWs in Chongqing.

The results of the survey revealed that over half (56.3\%) of the respondents only completed junior high school or less. Thus, MMWs tended to be poorly educated and consequently engaged in behaviors that placed them at risk of acquiring HIV, as has been found in other studies of internal Chinese migrants $[10,35]$.

In general, the HIV prevalence for 2010-2018 in our study was $0.6 \%$, which was approximately 11 times higher than the overall national HIV prevalence of China in $2011(0.058 \%)$. This result illustrated that MMWs in Chongqing were, indeed, at a high risk of HIV infection. Sentinel surveillance results for nine consecutive years showed that the positive rate of HIV among MMWs in Chongqing was on the rise $(0.2 \%$ to $0.9 \%, p<0.001)$. In the past few years, China has dramatically increased its coverage of screening and treatment for HIV, particularly among high-risk populations [33]. Although new occurrences have probably decreased slightly, due to some behavioral changes such as increasing consistent condom use during commercial sex $(20.5 \%$ to $54.0 \%, p<0.001)$ and non-regular sex $(10.9 \%$ to $47.3 \%, p<0.001$ ) with females in the past year, survival has improved owing to the increased coverage of antiretroviral therapy. Hence, an overall increase in the prevalence of HIV may occur. Generally, the infection rate of HCV among MMWs in Chongqing was $0.5 \%$, which was in agreement with the prevalence (0.5\%) estimated by the national surveillance system between 2009 and 2012 [36]. HCV prevalence showed a downward trend, from $0.5 \%$ in 2010 to $0.4 \%$ in 2018, probably as the risk of HCV transmission is mainly from unsafe blood injections, and such risks have been reduced substantially since the introduction of nucleic acid testing in blood banks by the Chinese government [37]. The average prevalence of syphilis was $0.8 \%$ higher than that in eastern China $(0.48 \%)$, probably due to the differences in educational level [16].

Interestingly, we found that the prevalence of HIV and HCV both dropped considerably from 2014 to 2016; further, syphilis prevalence also decreased greatly during 2014-2015 and 2016-2017. This may be due to the establishment of the trinity AIDS prevention and control model, including monitoring, treatment, and follow-up in Chongqing from 2013 to 2014 [38]. It is likely that the increased HIV 
prevalence from 2016-2017 is a result of all AIDS patients being recommended antiretroviral therapy since 2016, leading to more survival rates.

In recent years, a few studies have found that the problem of middle-aged and elderly people infected with HIV has become increasingly prominent [39]. Interestingly, we found that the elderly ( $\geq 50$ years old) and middle-aged (30-49 years old) MMWs were more likely to suffer from syphilis than the young group (16-29 years old). As people in China mainly consider sexual behaviors to be primary activities of young adults, less attention has been paid to elderly men infected with STIs participating in high-risk sexual behaviors [40]. However, we observed that the 16-29 age group was less likely to engage in commercial sex in the past year than the $\geq 50$ age group. The possibilities of consistent condom use during commercial sex in the past year in the 16-29 and 30-49 age groups were 2.606 and 1.632 times more than that in the $\geq 50$ age group; the possibilities of condom use in the last commercial sex in the 16-29 and 30-49 age groups were 1.805 and 1.360 times more than that in the $\geq 50$ age group; and the possibilities of consistent condom use during non-regular sex in the past year and condom use in the last non-regular sex in the 16-29 age group were 1.628 and 1.671 times more than those in the $\geq 50$ age group. The lesser frequency of using condoms during high-risk behaviors may have led to the higher STI prevalence in the $\geq 50$ age group. Another potential reason is that STIs can easily be transmitted among elderly men, as old age can cause a decline in cellular and humoral immune function. This condition could also be explained by the fact that young people are better educated and have more knowledge of HIV than their elderly counterparts, as supported by our results [9].

Given poor HIV-related awareness, persistent high-risk sexual behaviors could more likely result in HIV [41]. The surveillance data indicated that the correct HIV awareness rates among MMWs in Chongqing were less than $80 \%$ in 2011, 2013, and 2014; which was far from enough. Although some MMWs had a high awareness of HIV transmission, they were short of comprehensive HIV knowledge, such as prevention knowledge and testing services. A significant increase in the engagement in commercial sex $(7.7 \%$ to $13.3 \%, p<0.001)$ was observed among the participants during the study period, probably due to the increasing use of the internet to find high-risk sexual partners, such as sex workers [42]. This appeared to be a positive sign, considering the role of such behaviors in increasing the risk of acquiring HIV and other STIs [43]. We also observed a relatively low percentage of consistent condom use during commercial $(40.3 \%)$ and non-regular sex $(31.1 \%)$, similar to the findings of other studies [44-46]. Unfortunately, we did not investigate vaginal, oral, and anal sexualities during commercial and non-regular sexes separately. A large number of studies indicated that unprotected commercial sexual behavior is one of the main routes of HIV/AIDS transmission [47,48]. Several Chinese studies have explained that the primary reason given for condom use among migrants is contraception, instead of disease prevention [4].

Most rural-to-urban MMWs work in the city for a short period and then return to their home villages. Migrant workers have, thus, been identified as a "bridge population" for HIV infection from the high-risk population to the general population [49]. The primary direction of such spread has long been assumed to originate from migrants who become infected while away from home and then infect their rural partners when they return, which contributes to more rapid transmission of HIV [50]. HIV prevention for this enormous and increasing population would not only protect themselves, but also reduce the spread of HIV to their partners, family members, and their communities [8].

A long and continuous observation time and protocol uniformity were the main strengths of our study. Our work also had several important limitations, however. First, non-participation could be affected by their HIV sero-status, and subjects living with HIV could be selected repeatedly in nine years, which can have a potential impact on the overall HIV epidemic. Second, some recall bias may exist in some related behaviors in the previous year or in the last sexual encounter. Third, in these interviews, self-reported information bias due to the social desirability was another potential vulnerability, as respondents may have been influenced by what they feel is "correct." Fourth, the MMWs in our study were from only four occupational clusters of three districts in Chongqing, which limits the generalizability of the findings. Fifth, the cross-sectional design of our questionnaire may 
ignore other mixed factors. Finally, permanent MMWs were not included, but they may suffer from adverse conditions similar to non-permanent MMWs. Despite these limitations, this study has made important findings about the current and possible future contributions of MMWs to Chongqing's STI epidemic.

\section{Conclusions}

The overall HIV prevalence has slightly increased over the past nine years among MMWs in Chongqing, and HCV prevalence has decreased simultaneously. Compared with the young group, middle-aged and elderly MMWs were more likely to be infected with syphilis. Elderly MMWs were more inclined to engage in unprotected high-risk behaviors. Thus, evidence-based prevention and appropriate education related to increasing commercial sex and inadequate condom use during high-risk behaviors should be expanded for this vulnerable population, especially those aged 50 years and above.

Our study provides a preliminary investigation into the HIV, syphilis, and HCV epidemics among MMWs in Chongqing. Future work could adopt similar techniques to understand the epidemics in other Chinese cities or provinces, in order to help guide public health policies toward a directed STI intervention in China.

Author Contributions: Y.W. and R.L. drafted and revised the manuscript. G.W. and R.L. analyzed the data and interpreted the data. R.O. and Y.Z. supervised the implementation of the study and revamped the manuscript. M.Y. conceptualized and designed the study and edited, revised, and critically reviewed the manuscript. All authors have read and approved the manuscript, and they ensure the correctness of the contributions.

Funding: This work was supported by the Chongqing Yuzhong District Science and Technology Bureau (Grant no. 20190116).

Acknowledgments: We thank the support of all the team members for this study.

Conflicts of Interest: The authors declare no conflicts of interest.

\section{References}

1. Ortblad, K.F.; Lozano, R.; Murray, C.J.L. The burden of HIV: Insights from the Global Burden of Disease Study 2010. AIDS 2013, 27, 2003-2017. [CrossRef] [PubMed]

2. Prevention N.C.F.A. Update on the AIDS/STD epidemic in China and main response in control and prevention the second quater of, 2016. Chin. J. AIDS STD 2016, 22, 585. (In Chinese)

3. Hong, Y.; Bonita, S.; Xiaoming, L.; Hongmei, Y.; Danhua, L.; Xiaoyi, F.; Jing, W.; Rong, M. Rural-to-urban migrants and the HIV epidemic in China. AIDS Behav. 2006, 10, 421-430. [CrossRef] [PubMed]

4. He, N.; Jinling, Z.; Xiuhong, T.; Genming, Z.; Qingwu, J.; Roger, D. Knowledge, attitudes, and practices of voluntary HIV counseling and testing among rural migrants in Shanghai, China. AIDS Educ. Prev. 2009, 21, 570-581. [CrossRef] [PubMed]

5. Hesketh, T.; Lim, L.; Ye, X.; Wang, H.; Jiang, M.; Tomkins, A. HIV and syphilis in migrant workers in eastern China. Sex Transm. Infect. 2006, 82, 11-14. [CrossRef] [PubMed]

6. Zhong, F.; Boheng, L.; Huifang, X.; Weibin, C.; Lirui, F.; Zhigang, H.; Caiyun, L.; Kai, G.; Huixia, M.; Faju, Q.; et al. Increasing HIV and decreasing syphilis prevalence in a context of persistently high unprotected anal intercourse, six consecutive annual surveys among men who have sex with men in Guangzhou, China, 2008 to 2013. PLoS ONE 2014, 9, e103136.

7. Zhang, L.; Dandan, Z.; Baowen, Y.; Shangbo, W.; Yanlin, L.; Jian, W.; Xin, L.; Xiaoyun, S.; Hongyuan, L. Prevalence of HIV infection and associated risk factors among men who have sex with men (MSM) in Harbin, P. R. China. PLoS ONE 2013, 8, e58440. [CrossRef]

8. Li, L.; Morrow, M.; Kermode, M. Vulnerable but feeling safe: HIV risk among male rural-to-urban migrant workers in Chengdu, China. AIDS Care 2007, 19, 1288-1295. [CrossRef]

9. Dai, W.; Jian, G.; Jian, G.; Xiuping, X.; Hua, Y.; Yao, S.; Jie, G.; Tianhao, W.; Yao, L.; Jing, Z.; et al. Sexual behavior of migrant workers in Shanghai, China. BMC Public Health 2015, 15, 1067. [CrossRef]

10. Yang, B.; Zheng, W.; Christoph, M.S.; Shuzhuo, L. HIV knowledge among male labor migrants in China. BMC Public Health 2015, 15, 323. [CrossRef] 
11. Anderson, A.F.; Qingsi, Z.; Hua, X.; Jianfeng, B. China's floating population and the potential for HIV transmission: A social-behavioural perspective. AIDS Care 2010, 15, 177-185. [CrossRef] [PubMed]

12. El-Bassel, N.; Louisa, G.; Stacey, A.S.; Gaukhar, M.; Assel, T.; Sholpan, P.; Xin, M.; Mingway, C.; Leyla, I.; Tim, H.; et al. The Silk Road Health Project: How Mobility and Migration Status Influence HIV Risks among Male Migrant Workers in Central Asia. PLoS ONE 2016, 11, e0151278. [CrossRef] [PubMed]

13. Kishamawe, C.; Debby, C.J.V.; Mark, U.; Raphael, I.; Gabriel, M.; Borsboom, G.J.J.M.; Voeten, H.A.C.M.; Zaba, B.; Habbema, J.D.F.; de Vlas, S.J. Mobility and HIV in Tanzanian couples: both mobile persons and their partners show increased risk. AIDS 2006, 20, 601-608. [CrossRef] [PubMed]

14. Deane, K.D.; Justin, O.P.; Deborah, J. Linking migration, mobility and HIV. Trop. Med. Int. Health 2010, 15, 1458-1463. [CrossRef]

15. Liu, H.; Xiaoming, L.; Bonita, S.; Hui, L.; Guojun, L.; Xinguang, C.; Hongmei, Y.; Yan, H. Risk factors for sexually transmitted disease among rural-to-urban migrants in China: implications for HIV/sexually transmitted disease prevention. AIDS Patient Care STDS 2005, 19, 49-57. [CrossRef]

16. Hesketh, T.; Li, L.; Ye, X.; Wnag, H.; Jiang, M.; Tomkins, A. HIV and syphilis in migrant workers in eastern China. Sex. Transm. Infect. 2006, 82, 11-14. [CrossRef]

17. Weine, S.; Mahbat, B.; Sana, L.; Linda, O. HIV Sexual Risk Behaviors and Multilevel Determinants Among Male Labor Migrants from Tajikistan. J. Immigr. Minor. Health 2013, 15, 700-710. [CrossRef]

18. Cai, R.; Richardus, J.H.; Looman, C.W.; de Vlas, S.J. Trends in high-risk sexual behaviors among general population groups in China: A systematic review. PLoS ONE 2013, 8, e79320. [CrossRef]

19. Zhang, L. Migration and Privatization of Space and Power in Late Socialist China. Am. Ethnol. 2001, 28, 179-205. [CrossRef]

20. Weine, S.M.; Kashuba, A.B. Labor Migration and HIV Risk: A Systematic Review of the Literature. AIDS Behav 2012, 16, 1605-1621. [CrossRef]

21. Li, X.; Xiaoyi, F.; Danhua, L.; Rong, M.; Jing, W. Lesley Cottrell, Carole Harris, and Bonita Stanton HIV/STD risk behaviors and perceptions among rural-to-urban migrants in China. AIDS Educ. Prev. 2004, 16, 538-556. [CrossRef] [PubMed]

22. Wu, Z.; Sheena, G.S.; Yu, W.; Mary Jane, R.; Roger, D. Evolution of China's response to HIV/AIDS. Lancet 2007, 369, 679-690. [CrossRef]

23. Jia, Y.; Lu, F.; Sun, X.; Vermund, S.H. Sources of data for improved surveillance of HIV/AIDS in China. Southeast Asian J. Trop. Med. Public Health 2007, 38, 1041-1052.

24. Sun, X.; Ning, W.; Dongmin, L.; Xiwen, Z.; Shuquan, Q.; Lan, W.; Fan, L.; Katharine, P.; Lu, W. The development of HIV/AIDS surveillance in China. AIDS 2007, 21, S33-S38. [CrossRef] [PubMed]

25. Lin, W.; Sanny, C.; Nicole, S.; Zhongdan, C.; Keith, S.; Jesus García, C.; Marc, B. Is the HIV sentinel surveillance system adequate in China? Findings from an evaluation of the national HIV sentinel surveillance system. Western Pac. Surveill. Response J. 2012, 3, 61-68. [CrossRef]

26. Ge, L.; Li, D.; Li, P.; Guo, W.; Cui, Y. Population specific sentinel surveillance for HIV infection, syphilis and HCV infection in China, during 2010-2015. Dis. Surveill. 2017, 32, 111-117. (In Chinese)

27. Zhang, Y.; Qin, X.; Liang, Z.; Dihui, M.; Ling, L.; Rongrong, L.; Dali, Y.; Dong, Y. The AIDS epidemic and economic input impact factors in Chongqing, China, from 2006 to 2012: A spatial-temporal analysis. BMJ Open 2015, 5, e006669. [CrossRef]

28. Yang, S.; Alice, P.Y.C.; Qianying, L.; Ziqian, Z.; Yafei, L.; Yao, Z.; Zhengrong, Y.; Lin, Y.; Daihai, H. HIV epidemics in Shenzhen and Chongqing, China. PLoS ONE 2018, 13, e0192849. [CrossRef]

29. Guo, W.; Bao, S.; Lin, W.; Wu, G.; Zhang, W.; Hladik, W.; Abdul-Quader, A.; Bulterys, M.; Fuller, S.; Wang, L. Estimating the size of HIV key affected populations in Chongqing, China, using the network scale-up method. PLoS ONE 2013, 8, e71796. [CrossRef]

30. Agha, S.; Thankian, K. Equity in access to condoms in urban Zambia. Health Policy Plan. 2003, 18, $299-305$. [CrossRef]

31. Weller, S.C. A meta-analysis of condom effectiveness in reducing sexually transmitted HIV. Soc. Sci. Med. 1993, 36, 1635-1644. [CrossRef]

32. Zhou, Y.; Li, X.; Zhang, C.; Tan, G.; Stanton, B.; Zhang, X.; Cui, Y. Rates of HIV, syphilis, and HCV infections among different demographic groups of female sex workers in Guangxi China: Evidence from 2010 national sentinel surveillance data. AIDS Care 2013, 25, 1433-1441. [CrossRef] [PubMed] 
33. Qin, Q.; Weiming, T.; Lin, G.; Dongmin, L.; Tanmay, M.; Liyan, W.; Wei, G.; Yan, C.; Jiangping, S. Changing trend of HIV, Syphilis and Hepatitis C among Men Who Have Sex with Men in China. Sci. Rep. 2016, 6, 31081. [CrossRef] [PubMed]

34. Xia, C.; Yue, Z.; Wang, H. Evaluation of three automated Treponema pallidum antibody assays for syphilis screening. J. Infect. Chemother. 2018, 24, 887-891. [CrossRef]

35. Tousignant, C. Correspondence Reply. Semin. Cardiothorac. Vasc. Anesth. 2016, 30, e41-e42. [CrossRef]

36. Liu, C.R.; Li, X.; Po-lin, C.; Hui, Z.; Ji-Dong, J.; Xiaochun, W.; Ying-Ru, L.; Nick, W. Prevalence of hepatitis C virus infection among key populations in China: A systematic review. Int. J. Infect. Dis. 2019, 80, 16-27. [CrossRef]

37. Shi, L.; Wang, J.X.; Stevens, L.; Ness, P.; Shan, H. Blood safety and availability: continuing challenges in China's blood banking system. Transfusion 2014, 54, 471-482. [CrossRef]

38. Zhou, C.; Zongliang, C.; Guohui, W. Progress and strategy of implementing three $90 \%$ targets of AIDS prevention and control in Chongqing. Mod. Med. Health 2018, 34, 1759-1761. (In Chinese)

39. Vollmer, S.; Harttgen, K.; Alfven, T.; Padayachy, J.; Ghys, P.; Barnighausen, T. The HIV Epidemic in Sub-Saharan Africa is Aging: Evidence from the Demographic and Health Surveys in Sub-Saharan Africa. AIDS Behav. 2017, 21, 101-113. [CrossRef]

40. Xiao, G.; Bin, P.; Ying, H.; Dou, Q.; Min-Qing, L.; Yu, G.; Feng-Lan, Z.; Hong, Y.; Yu, J.; Wei-Kang, Z.; et al. Characteristics influencing high-risk sexual behaviours in elderly men. Int. J. STD AIDS 2019, 30, 353-361. [CrossRef]

41. Marks, G.; Crepaz, N.; Senterfitt, J.W.; Janssen, R.S. Meta-analysis of high-risk sexual behavior in persons aware and unaware they are infected with HIV in the United States: implications for HIV prevention programs. J. Acquir. Immune Defic. Syndr. 2005, 39, 446-453. [CrossRef] [PubMed]

42. Lau, J.T.F.; Kim, Y.H.; Jean, H.K.; Lau, M.; Tsui, H.Y. Prevalence and risk behaviors of Chinese men who seek same-sex partners via the internet in Hong Kong. AIDS Educ. Prev. 2003, 15, 516-528. [CrossRef]

43. Feng, Y.; Zunyou, W.; Roger, D.; Guangming, Q.; Li, L.; Xiaodong, W.; Jun, W.; Linglin, Z. HIV/STD prevalence among men who have sex with men in Chengdu, China and associated risk factors for HIV infection. J. Acquir. Immune Defic. Syndr. 2010, 53, S74-80. [CrossRef] [PubMed]

44. Hong, Y.; Stanton, B.; Li, X.; Yang, H.; Lin, D.; Fang, X.; Wang, J.; Mao, R. Rural-to-urban migrants and the HIV epidemic in China. AIDS Behav. 2006, 10, 421-430. [CrossRef] [PubMed]

45. He, N.; Detels, R.; Chen, Z.; Jiang, Q.; Zhu, J.; Dai, Y.; Wu, M.; Zhong, X.; Fu, C.; Gui, D. Sexual behavior among employed male rural migrants in Shanghai, China. AIDS Educ. Prev. 2006, 18, 176-186. [CrossRef] [PubMed]

46. Li, W.; Junjun, J.; Jinming, S.; Bingyu, L.; Wei, D.; Jiegang, H.; Bo, Q.; Halmurat, U.; Chaohui, Z.; Qianqiu, W.; et al. Commercial Sexual Behaviors Among Male Rural-to-Urban Migrants in Western China: Implications for HIV Prevention. Asia Pac. J. Public Health 2017, 29, 388-400. [CrossRef] [PubMed]

47. Yang, X.; Li, S.; Attane, I.; Feldman, M.W. Commercial sex behaviors among involuntary male bachelors: findings from a survey of migrants in Xi'an, China. J. Public Health 2015, 37, 305-312. [CrossRef]

48. Morison, L.; Weiss, H.A.; Buve, A.; Carael, M.; Abega, S.C.; Kaona, F.; Kanhonou, L.; Chege, J.; Hayes, R.J. Commercial sex and the spread of HIV in four cities in sub-Saharan Africa. AIDS 2001, 15, S61-69. [CrossRef]

49. Tiruneh, K.; Wasie, B.; Gonzalez, H. Sexual behavior and vulnerability to HIV infection among seasonal migrant laborers in Metema district, northwest Ethiopia: a cross-sectional study. BMC Public Health 2015, 15, 122. [CrossRef]

50. Lurie, M.N.; Brian, G.W.; Khangelani, Z.; David, M.; Geoff, P.G.; Michael, D.S.; Joel, G.; Salim, S.A.K. Who infects whom? HIV-1 concordance and discordance among migrant and non-migrant couples in South Africa. AIDS 2003, 17, 2245-2252. [CrossRef]

(C) 2020 by the authors. Licensee MDPI, Basel, Switzerland. This article is an open access article distributed under the terms and conditions of the Creative Commons Attribution (CC BY) license (http://creativecommons.org/licenses/by/4.0/). 